This item was submitted to Loughborough's Research Repository by the author.

Items in Figshare are protected by copyright, with all rights reserved, unless otherwise indicated.

\title{
Young people's knowledge and understanding of health, fitness and physical activity: issues, divides and dilemmas
}

PLEASE CITE THE PUBLISHED VERSION

http://dx.doi.org/10.1080/13573322.2016.1228047

\section{PUBLISHER}

(c) Taylor \& Francis

\section{VERSION}

AM (Accepted Manuscript)

\section{PUBLISHER STATEMENT}

This work is made available according to the conditions of the Creative Commons Attribution-NonCommercialNoDerivatives 4.0 International (CC BY-NC-ND 4.0) licence. Full details of this licence are available at: https://creativecommons.org/licenses/by-nc-nd/4.0/

\section{LICENCE}

CC BY-NC-ND 4.0

\section{REPOSITORY RECORD}

Harris, Josephine P., Lorraine Cale, Rebecca Duncombe, and Hayley Musson. 2019. "Young People's Knowledge and Understanding of Health, Fitness and Physical Activity: Issues, Divides and Dilemmas". figshare. https://hdl.handle.net/2134/22966. 
Title:

Young people's knowledge and understanding of health, fitness and physical activity: Issues, divides and dilemmas

\section{Authors and contact details:}

Dr Jo Harris, Dr Lorraine Cale, Dr Rebecca Duncombe and Hayley Musson School of Sport, Exercise and Health Sciences

Loughborough University

Loughborough

Leicestershire

LE11 3TU

UK

\section{*Corresponding author:}

Dr Jo Harris

School of Sport, Exercise and Health Sciences

Loughborough University

Loughborough

Leicestershire

LE11 3TU

UK

Tel: +44 (0)1509223250

E-mail: j.p.harris@lboro.ac.uk 


\title{
Title
}

Young people's knowledge and understanding of health, fitness and physical activity: Issues, divides and dilemmas

\begin{abstract}
Critical discourse analysis was used to explore and discuss data on young people's knowledge and understanding of health, fitness and physical activity, selected from a wider study which focused on the role of secondary schools in effectively promoting physical activity. A mixed methods approach was utilised, involving an online survey to teachers in all state secondary schools in the United Kingdom ( $n=603$ responding schools) and case studies centred on eight randomly selected state secondary schools from nine Government regions across England. Within each case study school, teacher interviews and pupil focus groups were conducted involving 17 teachers and 132 children aged 12-15 years respectively. The healthism discourse was evident in the way young people talked about health, fitness and physical activity and two key themes emerged, these being: i) issues with young people's knowledge and understanding of health, fitness and physical activity in the form of reductive, limited and limiting conceptions; conceptual confusion; a preoccupation with appearance, weight, fat, shape and size; limited progression in learning; and complexities in understandings; and ii) divides between young people's health knowledge and health behaviour, and dilemmas underpinning these divides. Improved understanding of issues with young people's knowledge and understanding of health, fitness and physical activity and of divides and dilemmas regarding associated behaviours should assist in developing critical pedagogies which challenge the dominance and stability of the healthism discourse and more effectively promote healthy, active lifestyles amongst young people.
\end{abstract}

\section{Keywords}

young people; health; fitness; physical activity; physical education; pupil voice; pedagogy 


\section{Introduction}

In the past, schools have been viewed as wholly suitable vehicles for the promotion of healthy, active lifestyles amongst young people (Cale, 2000; Cardon \& Bourdeaudhuij, 2002; Shephard \& Trudeau, 2000). However, schools' effectiveness in addressing society's health problems has been questioned given that most factors influencing young people's health (such as genetics, the environment and family modelling) are beyond the influence of schools, schools are increasingly asked to address public health concerns (such as poor nutritional behaviours, unwanted pregnancies and tobacco use) yet are themselves grappling with issues associated with competing elements within a finite curriculum, insufficient training and financial constraints, and the core business of schools is focused on educational outcomes, not reducing health problems (Gard \& Pluim, 2014; St. Leger, 2004; Thomas Thomas, 2004).

Within this context, however, the promotion of healthy lifestyles continues to be represented in curricula across the world (Australian Curriculum and Reporting Authority, 2011; Department for Education, 2013). The National Curriculum for physical education (PE) in England, for example, has as one of its main aims that pupils will lead healthy, active lives (Department for Education, 2013). This is based on the rationale that a physically active lifestyle leads to health benefits (Pasco et al., 2011; Lee et al., 2012; Wen \& Wu, 2012), that being active in childhood can lead to a more active adult lifestyle (Harro \& Riddoch, 2000), and that knowledge and understanding of physical activity and health concepts may be associated with improved physical activity behaviours (DiLorenzo et al., 1998; Roth \& Stamatakis, 2010; Zhu, Safrit \& Cohen, 1999). However, whilst all of this might suggest a reasonably straightforward relationship between physical activity and health knowledge, behaviour and outcomes, the reality is far from unproblematic. The reasons underlying physical activity behaviours are complex and go well beyond individual-level correlates (such as age, sex and self-efficacy) and physical and social environment determinants (such as economic conditions, societal norms and urbanisation) to genetic factors contributing to the 
propensity to be physically active and evolutionary factors that might predispose to inactivity (Bauman et al., 2012). This suggests that schools' role in educating about health, whilst seemingly logical, is far from straightforward.

Indeed, despite the promotion of active lifestyles being a central aim of PE curricula for many years now, there is little evidence that it has significantly impacted on young people's physical activity knowledge and behaviour. Young people have been found to have misconceptions and misunderstandings about health, physical activity and fitness since the early 1990s (Brusseau et al., 2011; Burrows \& Wright, 2004; Burrows et al., 2002, 2009; Desmond et al., 1990; Dixey et al., 2001; Harris, 1993, 1994; Keating et al., 2009; Kulinna, 2004; Lee \& Macdonald, 2009, 2010; Merkle \& Treagust, 1993; O'Shea \& Beausoleil, 2012; Placek et al., 2001; Powell \& Fitzpatrick, 2015; Stewart \& Mitchell, 2003) and Government inspectors of schools in England identified weaknesses in pupils' knowledge and understanding of health and fitness over a decade ago (Office for Standards in Education, 2005). Further, in England, only 10\% of $12-15$ year olds were found to be familiar with physical activity recommendations for their age (Roth \& Stamatakis, 2010) and only $16 \%$ of girls and 21\% boys aged 5-15 years achieve recommended levels of physical activity of at least one hour of moderately intense activity per day (Health and Social Care Information Centre, 2015).

It has been suggested that young people's inadequate and/or inaccurate understandings of health, fitness and physical activity are the consequence of how they are taught in schools and addressed in popular culture such as the media (Burrows \& Wright, 2004; Burrows et al., 2002; Lee \& Macdonald, 2009, 2010). Approaches steeped in healthism discourse which is based on the notion that health can be achieved 'unproblematically through individual effort and discipline, directed mainly at regulating the size and shape of the body' (Crawford, cited in Kirk and Colquhoun, 1989, p. 149) have led to young people developing reductive, limited and limiting conceptualisations of health, fitness and physical activity (Burrows \& Wright, 
2004; Burrows et al., 2002; Lee \& Macdonald, 2009, 2010). Thus, well meaning but inadequately prepared teachers holding narrow, reductive views of health, fitness and physical activity themselves may be contributing to young people's engagement with healthism discourses (Lee \& Macdonald, 2009, 2010), resulting in schools falling well short of their potential to promote healthy, active lifestyles.

Interest in this area of study stemmed from awareness that limited research on young people's knowledge and understanding of health, fitness and physical activity had been conducted in the United Kingdom (UK), and from the belief that increased understanding of this and its underlying reasons should assist in developing critical pedagogies which more effectively promote active lifestyles. This paper reports on selected findings from a research project commissioned by the British Heart Foundation National Centre for Physical Activity and Health which focused on supporting secondary schools in the effective promotion of physical activity and health. The paper presents and discusses data from the first phase of the study reflecting young people's knowledge and understanding of health, fitness and physical activity. A number of recommendations are offered to enhance associated teaching and learning and to affect positive behavioural change. Prior to describing the study's methodology, an overview of the literature on children's knowledge and understanding of health, fitness and physical activity is presented.

Young people's knowledge and understanding of health, fitness and physical activity

Desmond and colleagues' (1990) study of the fitness conceptions of high school students in the USA revealed that a high proportion of the students held misconceptions about fitness, with many being uncertain about the validity of the statement 'no pain, no gain' and believing that how fast someone runs is more important than how far they run. Harris' research in the UK, also in the early 1990s, revealed that young people's understanding of health, fitness and physical activity was limited, associating health and fitness, for example, with being thin and being good at sport; she also found that young people's knowledge was largely 
unrelated to the way in which they lived their lives (Harris, 1993, 1994). Around the same time, Merkle and Treagust (1993) reported on a study of Australian students' knowledge of health and fitness which similarly revealed limited conceptions such as students mostly relating fitness to big muscles, running without breathlessness, and not being overweight. Merkle and Treagust (1993) also found that, despite many students being aware that they should eat healthily and exercise, they did not necessarily eat the 'right food' (p.357) or participate in regular physical activity; they also reported that students with naive conceptions about health and fitness components believed in chance for their personal health.

Some years later, research from the USA reported that 11-12 year old students had difficulty defining physical activity and fitness, equated fitness to being thin and looking good, and had little knowledge about fitness components, activities that improve fitness, and principles of training (Placek et al., 2001); they also reported that many students believed that jogging improves strength and that a specific exercise can lead to fat loss in a specific area. Stewart and Mitchell (2003, p. 550) similarly found a lack of foundational knowledge, misconceptions, and incorrect generalisations about fitness amongst high school students in the USA and described student knowledge and conceptions of fitness concepts as 'narrow, vague, and often incorrect'. Kulinna (2004) also found that more than $50 \%$ of elementary pupils in the USA were unable to list four aerobic and nonaerobic physical activities correctly.

In New Zealand also, whilst students were found to be familiar with the relationship between health, fitness and physical activity, they often conflated fitness with health, associated fitness with 'non-fatness' and with laziness, and viewed exercise and diet as key moderators in the process of maintaining health (Burrows, Wright \& Jungersen-Smith, 2002). Burrows and colleagues (2002) expressed concern about the way in which the relationship between these concepts was accepted unproblematically and suggested that this represented a worrying acceptance of discourses associated with guilt, the self-monitoring of the body and the denial of pleasure associated with physical activity. Burrows and her colleagues 
(Burrows \& Wright, 2010, p. 201) have more recently commented on children's certainties about health and how children delineate 'a remarkably clear line between healthy and unhealthy practices'; their findings have also focused on the sources of young people's understandings and this has led them to posit that children's views are a reflection of how health and fitness is being taught in schools and promoted in the general public.

Even in recent years, studies have continued to report limited knowledge and understanding of health, fitness and physical activity concepts amongst students. For example, Keating and colleagues (2009) revealed a lack of health related fitness knowledge amongst American students, and Brusseau, Kulinna and Cothran (2011) found that Native American children had minimal understanding of basic physical activity and healthy behaviour concepts, with only $7 \%$ of students in their study being able to describe why physical activity was important and only about half being able to explain why physical activity was good for them. Furthermore, Roth and Stamatakis (2010), drawing on the data of approximately 2000 children aged 12-15 years from the 2007 Health Survey in England, found markedly low familiarity with physical activity guidelines yet an association between knowing the guidelines and an increased likelihood of meeting them, an association that was stronger in girls than in boys.

More recently, Powell and Fitzpatrick (2015) examined how New Zealand primary school children constructed notions of fitness, health and the body and found that obesity discourses and body pedagogies 'collided' to shape understandings of fitness lessons in ways inextricably connected with the avoidance of being fat. For example, the children considered that being fit was demonstrated by a 'correct' corporeal appearance and assumed that fitness lessons increased fitness (ibid, 2015, p.463). Like Burrows and her colleagues, Powell and Fitzpatrick (2015) considered the source of children's ideas about the body and concluded that body pedagogies inside and outside the school gates had shaped these in ways that excluded other understandings of bodies, health and physical 
activity which challenge children to critique and reconstruct normative discourses and practices around the body.

Recurring findings amongst many of the studies of children's conceptualisations of health and fitness are that they are usually viewed as primarily corporeal notions, are often used interchangeably, and appearance is a prominent feature. For example, with respect to the latter, Placek and colleagues (2001) found that thinness was viewed as a sign of fitness and O'Shea and Beausoleil (2012) showed that young people viewed excess weight as a barrier to health. Dixey and colleagues' (2001) study in England found that, whilst young children had learned orthodox messages surrounding health, fat and overweight, there was much complexity in their understandings, for example many did not believe that 'thin is good, fat is bad' and did not tend to link weight control with exercise.

In summary, the worldwide literature on young people's knowledge and understanding of health, fitness and physical activity across many countries and over many years reveals reductive, limited and limiting conceptualisations, reproduced by teaching approaches, public health messages and popular culture, all of which are influenced by the dominant discourse of healthism.

\section{Methods}

This study was part of a wider research project focusing on the role of secondary schools in effectively promoting physical activity, the specific aims of which were: to establish the needs of schools with respect to the promotion of physical activity; to develop, implement and evaluate support for schools to effectively promote physical activity; and to evaluate the impact of the support on schools, teachers and young people. A mixed methods approach was adopted, incorporating qualitative and quantitative viewpoints, data collection and analysis to address the aims of the study (Johnson et al, 2007). The data collection methods involved an online survey emailed to all state secondary schools in the UK and eight case studies centred on randomly selected state secondary schools from eight (of the 
nine) Government regions in England. Within each case study school, face to face interviews were conducted with teachers, focus groups were organised with pupils aged 1115 years, and telephone interviews took place with parents of the pupils involved in the focus groups. All data collection took place during 2011. Of particular relevance to this paper were data from the focus groups reflecting pupils' knowledge and understanding of health, fitness and physical activity, and data from the online survey and interviews exploring teachers' views on young people's knowledge and understanding of health, fitness and physical activity and on the relationship between this and their health behaviours.

The online survey of teachers was emailed to all secondary schools in the UK (England, Northern Ireland, Wales and Scotland) for which e-mail addresses could be obtained, a total of 3990 schools. The survey link was sent to the head teacher in the first instance with a request to forward it to a relevant person in the school. In total, responses were received from 603 schools which represented an overall response rate of 15.1\%. This paper includes a focus on responses to selected questions in the survey such as: 'Do you feel there is a difference between what pupils know and understood about healthy, active lifestyles compared to the actual lifestyles that they lead?'.

Individual or small group interviews took place with a total of 17 staff in the case study schools, these included 15 qualified teachers (13 of whom were specialist PE teachers) and two members of support staff. These individuals comprised of a mix of males and females who held various roles in the school (such as Head of Physical Education and Head of Personal, Social and Health Education) and were deemed by the headteacher to be appropriate to interview about promoting healthy, active lifestyles. The interview schedule included questions such as 'What do you think young people know and understand about healthy, active lifestyles? What else do they need to know? Do you feel that there is a difference between what pupils know about healthy, active lifestyles compared to the actual lifestyles that they lead? If so, can you give any examples and/or explanations?. 
Thirty eight focus groups were conducted involving a total of 132 pupils (83 girls and 49 boys). Each focus group involved three to eight randomly selected girls and boys from particular year groups and lasted between 30 and 60 minutes. Focus group schedules included questions relating to young people's knowledge and understanding of health, fitness and physical activity and their physical activity behaviour. These included: What does being healthy (fit/active) mean to you? What do you think it means to lead a healthy (fit/active) lifestyle? How would you describe a healthy (fit/active) person? Do you think you are healthy (fit/active)? Prior to the commencement of the study, ethical consent was sought and granted from the University's ethics committee and consent was obtained from all parties concerned.

Quantitative data and responses to open-ended questions from the online survey were downloaded into Excel. The quantitative data were converted by Survey Monkey into percentages and analysed, whilst the open ended responses were coded, categorised into themes and quantified. All interviews and focus group discussions were transcribed and responses entered into Excel. Analysis of this data involved organising responses into emerging categories and themes (Ritchie \& Lewis, 2003), quantifying the responses for each category/theme, and selecting key illustrative quotations.

\section{Issues and Divides}

The findings from the study are reported under two key themes which emerged from analysis of the data: issues with young people's knowledge and understanding of health, fitness and physical activity; and divides between young people's knowledge and understanding of health, fitness and physical activity and associated behaviours. The discussion of the findings draws on critical discourse analysis which is a problem-oriented research movement which views language as socially constitutive and shaped and uses rational thinking to question arguments and prevailing ideas (Fairclough, Mulderrig \& Wodak, 
2011). The findings are expressed in terms of the proportion represented by the responses, as follows: nearly all (over 90\%); the vast majority (over 75\%, less than $90 \%$ ); most (over $50 \%$, less than $75 \%$ ); many (over $30 \%$, less than $50 \%$ ); some (over $10 \%$, less than $30 \%$ ); and few (less than 10\%).

Issues with young people's knowledge and understanding of health, fitness and physical activity

The findings revealed a number of issues with young people's knowledge and understanding of health, fitness and physical activity. In particular, these concepts were mostly viewed in reductive, limited and limiting ways. This was exemplified by the vast majority of young people in the study interpreting 'being healthy' in the physical sense with typical responses including:

Like having a balanced diet and doing physical activities in school and out of school to keep fit (Case Study School A, 14 years old).

Being able to do a lot of exercise... and not run out of breath straightaway (Case Study School E, 14 years old).

Being healthy means like staying fit and active (Case Study School E, 12 years old).

The vast majority of the young people in the study identified physical activity as 'healthy', as exemplified by one 15 year old (Case Study School B) who stated that 'if you are inactive, you are not very healthy'. However, there was limited awareness and understanding amongst the young people of social and psychological aspects of health (such as being with friends, getting on with others, feeling good, sleep, rest, relaxation) and only few of them mentioned pleasure or fun associated with being active. These findings resonate with those previously reported by others such as Burrows and her colleagues (2002) who described students' conceptions of health as predominantly 'corporeal'. 
The findings also revealed some degree of conceptual confusion in that, for most of the young people, there seemed to be little or no clear distinction between the terms health, fitness and physical activity. Indeed, one young person in the study admitted to being confused, stating:

What is fitness though? That is what I want to know. I just think fitness and being healthy are the same thing....' (Case Study School C, 15 years old).

and a 13 year old from Case Study School G described a fit person as 'more happy in a way, not grumpy and all that'. Some conceptual confusion was also evidenced in responses to the question 'what three actions could you do over the next few months to improve your fitness?' such as:

Eat more fruit, have more glasses of water and do more exercise (Case Study School A, 12 years old).

Eat a balanced diet (Case Study School A, 15 years old).

Sleep properly (Case Study School A, 15 years old).

Furthermore, most of the young people in the study described a fit person as someone who 'can do lots of exercise without getting tired' (Case Study School B, 12 years old) and 'who eats the right food at the right times' (Case Study School C, 15 years old), with one individual stating:

I do have a friend that is quite fit. I think she is fit because I have been round to her house a lot of times, like when she is having tea... and every time she has like a plate of like carrots or something healthy (Case Study School D, 12 years old).

The above quotations suggest a conflation of fitness with health which is consistent with the findings of previous researchers such as Harris $(1993,1994)$ and Burrows et al. (2002). 
When prompted about any distinctions between the concepts, the young people in the study generally associated health with diet, and fitness with exercise, as exemplified by the following quotations:

When you say healthy, you think fruits and food, and when you say fit, you think exercise, running, weights (Case Study School H, 12 years old).

I think health is more food and what you eat, and fitness is more the physical stuff what you are doing (Case Study School E, 15 years old).

My brother, he's fit but he's unhealthy because he eats a lot of junk food but he stays fit because he runs and burns it off (Case Study School G, 15 years old).

Furthermore, most of the young people in the study associated becoming fit with frequent exercise and considered that enhanced fitness depends on the type of exercise performed (frequent examples cited included running, swimming, star jumps and Wii Fit Plus) and on its intensity and duration. Whilst these findings indicated a reasonably sound understanding of 'fitness', it did not acknowledge potential fitness gains from incidental or routine moderateintensity physical activity (such as walking) nor informal recreational activities that young people might do for fun (such as scootering and roller skating).

Another issue arising from the study was confirmation of the prominence of appearance, weight, shape and size in children's conceptualisations of health, fitness and physical activity which has been detected by many others (e.g. Burrows et al., 2002; Harris, 1993, 1994; Placek et al., 2001). For example, most of the young people in the study referred to a person's appearance as indicative of their health and generally considered thin or slim people to be healthy and fat people to be unhealthy. Two 15 year olds from Case Study School B considered a healthy lifestyle to be important because 'you don't want to get fat' and 'so people don't like judge you on your size'. Most of the young people in the study also associated fitness with a particular appearance and body shape, one that is thin, toned, muscular and strong, and one 13 year old (Case Study School F) considered that fitness 
could be measured 'by seeing how heavy you are'. These perspectives may have been influenced by the slang interpretation of 'fit' in the UK as sexy and/or physically attractive. However, views conflating health and fitness with physical attractiveness and thinness are consistent with studies internationally (Burrows \& Wright, 2004; Burrows et al., 2002, 2009; Lee \& Macdonald, 2009, 2010).

Most of the young people viewed physical activity as important to health, mainly due to its influence on appearance, weight, size and shape. However, they did not seem to appreciate that health, fitness and physical activity are about more than appearance, weight, shape and size, and that individuals of all shapes and sizes can be healthy, fit and active.

A further issue emanating from the study was that, whilst most of the young people revealed some knowledge of the contribution of physical activity to health and fitness, they demonstrated limited understanding of this in that they seemed unable to develop their initial responses or to provide specific examples. Indeed, most had difficulty in elaborating on how physical activity benefits health. For example, in response to the question 'how does being active affect your body?', one 13 year old (Case Study School A) replied 'your heart beats faster' and then to the follow-up prompt 'why is it important that your heart beats faster?', stated 'Because when you get older then you won't have that opportunity anymore'. Further, whilst most of the young people were able to identify some specific physical health benefits of physical activity such as prevention of obesity and reduced risk of heart attacks, other physical benefits such as lowered blood pressure and increased bone density, and psychological benefits such as enhanced self-esteem and reduced anxiety and depression were not identified.

Also, when discussing fitness, most of the young people in the study focused on general fitness with minimal evidence of an understanding of specific components of fitness. Whilst national curricula do not generally specify the need for learning about these components, this has been viewed as an appropriate learning outcome for older pupils (Harris, 2000; 
Placek et al, 2001). Furthermore, the study revealed little notable difference in the young people's knowledge and understanding of health, fitness and physical activity across the three year age span from 12 to 15 years, suggesting limited progression in learning during this period of time. Whilst the older pupils generally communicated with greater confidence and clarity, the content of the responses were similarly superficial and lacking in detail. Limited depth of understanding of concepts and of their relevance to young people's lives has also been found by previous researchers such as Brusseau et al. (2001), Placek et al. (2001) and Stewart \& Mitchell (2003) and was detected by Government inspectorate in schools in England (Ofsted, 2005). Given increased expectations on schools to promote healthy behaviours, this suggests a need for a radical re-think of approaches to achieve this and enhanced support for teachers in their role as health promoters especially with respect to deepening their pupils' understandings and relating these to young people's everyday lives.

A further issue arising from the findings was that many of the young people associated health and fitness with being good at sport. For example, one 13 year old stated:

I think active is more overall sport, like you have got people that are good at one thing and not so good at others, but I would say active is like good in quite a lot of sports (Case Study School E, 15 years old).

Furthermore, although nearly all of the young people offered numerous examples of physical activities, these were mostly in the name of specific sports. It is a concern that young people do not hold a broad conceptualisation of physical activity and its potential contribution to health as this may limit their physical activity participation due to a perceived notion that they are not good at sport or not engaging in activities which are health-enhancing. This issue also arose in a study of young women in rural Australia who did not consider walking, cycling and physical labour to be legitimate health-enhancing physical activities, and therefore 
perceived themselves as not taking responsibility for their own health and fitness (Lee \& Macdonald, 2009, 2010).

The findings did also reveal broader and more complex conceptualisations of health, fitness and physical activity amongst some of the young people. For example, two thirteen year olds from Case Study School B showed awareness of health being associated with positive emotions such as involving 'having a healthy mind' and 'not being stressed'. Comments from older pupils at the same school included:

Being healthy is if they are happy, their emotions (Case Study School B, 14 years old) It's about feeling good about yourself (Case Study School B, 15 years old)

A few pupils from this school also revealed some knowledge of the effect of physical activity on cognitive functioning and academic performance, as exemplified by the following quotations:

...being active and doing physical activity can also help with your education because it gets more oxygen to your brain so you can learn more (Case Study School C, 13 years old).

You will look better, you will feel better. Mentally like your brain will work, your thinking will be much sharper (Case Study School C, 15 years old).

This may suggest that Case Study School B possibly addresses the teaching of health in an holistic way, in comparison with the other case study schools which is an area worthy of further study and exploration.

In addition and, as found by Dixey and colleagues (2001), a few of the young people in the study held broader and more complex understandings of health, fitness and physical activity recognising, for example, that: 
Not all skinny people are healthy. You lot all sit on your Xboxs and none of you look fat (Case Study School H, 15 years old).

In addition, a 13 year old from Case Study School F who stated that fitness is related to 'not being unwell and being able to perform activities' clearly viewed it as more than just a physical concept, adding:

I suppose you could be like mentally fit so your mind is able to cope with more stuff but then you could be physically fit where you're like muscly and strong and stuff (Case Study School F).

Furthermore, whilst the vast majority of the young people in the study identified physical activity as 'healthy', most also identified risks associated with being active, such as sustaining injuries when playing sport and doing too much activity as a result of "pushing yourself too hard' (Case Study School B, 15 years old) or 'overdoing it which means you are damaging your body' (Case Study School D, 15 years old).

Complex conceptualisations were also evident in responses from other young people such as a 13 year old (Case Study School C) who somewhat unusually made reference to longer term health benefits of being active and stated:

I think it's quite important because the things you do now will affect when you're older, like when you're 60 and stuff. It will affect your body and you won't be able to do so much.

Divides between young people's knowledge and understanding of health, fitness and physical activity and associated behaviours

With reference to health behaviours, the vast majority of the young people in the study considered themselves 'healthy enough' or 'kind of healthy', predominantly because they 
were not overweight, did not eat too much junk food, and exercised. Some, however, viewed themselves as unhealthy, mainly because they had a poor diet and/or were not active; in relation to the former, one individual stated:

I don't actually think I am healthy... because like with the stuff that you should eat at home...Mum tells you eat this and it is like, no I don't like it. She says it is good for you but you say I don't care because you don't want to eat it because you don't like what it is (Case Study School A, 15 years old).

Many of the young people in the study described themselves as 'sometimes' or 'quite' active or 'active enough' although the vast majority had limited knowledge about how much physical activity they should do, with responses varying from 20 minutes to five hours a day, the most common suggestion being two hours per week which was the amount of time they had for PE per week. Many showed awareness that the amount of physical activity required could be accumulated throughout the day; however, a few stated that it should be continuous. Limitations and confusion about physical activity recommendations have also been found in England amongst PE trainee teachers (Harris, 2014) and young people (Roth and Stamatakis, 2010). This is disappointing given the number of years that public physical activity for health recommendations have been available and given awareness that increasing young people's knowledge of such recommendations can facilitate increased activity levels for some young people. It suggests major limitations in how physical activity for health recommendations are marketed, disseminated and implemented.

The most common reasons cited by the young people in the study for not being active or more active than they currently were included being lazy, feeling tired, being ill, and cold or wet weather. Indeed, inactive people were mostly described as fat, lazy, lethargic and/or tired. Most of the young people were able to suggest ways in which they could be more active such as going out more, doing more sport or getting involved with more activities, helping with housework, and going, or taking the dog for, a walk. 
Despite awareness of various ways of increasing their activity levels, the findings revealed an acknowledged divide between health knowledge and understanding and associated health behaviours. For example, many of the young people in the study were acutely aware of gaps between their health knowledge and understanding and their health behaviour(s), with one stating:

You might learn to like eat healthily but not necessarily eat healthy foods (Case Study School F, 13 years old).

Reasons suggested for such gaps included: 'it's too much effort to be healthy', I can't be bothered', 'I'm too lazy' and 'it's quicker/easier not to be healthy'. One stated:

You can grab fast food a lot quicker than you can cook a proper home cooked meal. It takes longer and nowadays parents don't seem to have the time because they've got jobs and stuff and they kind of like rush dinner basically (Case Study School A, 14 years old).

Teachers also acknowledged this divide between health knowledge and health behaviour; indeed, the vast majority of responses to the online survey and teachers in all eight case study schools referred to a gap between young people's knowledge and understanding about healthy, active lifestyles and their actual lifestyles. The most common reasons proposed by teachers for this 'gap' included: a discrepancy between what young people are taught at school and what is promoted or available at home; parental knowledge lagging behind pupil knowledge (e.g. parents not buying the 'right' food or not cooking healthily or not encouraging/enabling their children to be physically active); peer pressure to lead unhealthy, inactive lifestyles; an unhealthy/inactive lifestyle being easier and cheaper; young people preferring unhealthy options; young people just not being worried or caring about their health; and/or a lack of facilities in the community and/or inadequate bus services to transport children to and from activities. Illustrative quotations from the teachers include: 
Children are aware of what is required to lead a healthy lifestyle but, as parents are responsible for the lifestyle at home, the messages we give children aren't always applied at home (Online Survey).

Pupils are very influenced by their peers and will often do what their friends do rather than what they would rather do or know would be better for them (Online Survey).

Yes I think there is a huge gap...especially in this school. I think our students... have a comprehensive knowledge of what they should do and a massive imbalance in what they really do (Case Study School C).

Oh yes, I think some of them, they go home and sit in front of a computer all evening and eat rubbish, I would imagine... Yes, and sometimes it is hard for us to say, you know, we can be at school saying "You should have this" but if they haven't got it, you know ok, you could look at, yes they are getting more independent so yes they could go to the cupboard and make their own choices but if the things aren't in the cupboard, it is hard for them (Case Study School D).

The findings of this study are consistent with previous studies going back to the early 1990s in that a mismatch was found between young people's health knowledge and health behaviour and it reveals a number of interesting complexities. For example, young people seem to know that being active contributes to good health but are unclear about which physical activities are health-enhancing and, whilst they have some knowledge about why they should be active, they are not necessarily active for range of reasons such as choosing not to be, being unsure of what to do, or not having easy access to physical activity. It may also be that some young people who are not overweight or obese consider that they do not need to be active as they mainly associate the benefits of physical activity with obesity. All of this serves to exemplify the challenge and complexity of behaviour change and the need 
for sophisticated teaching and learning approaches that guide young people towards adopting healthy, active lifestyles. Critical approaches which challenge the dominance of the healthism discourse may lead to more flexible understandings of physical activity and health, independent of weight (Lee \& Macdonald, 2009, 2010). In addition, given that teachers in this study (and, to some extent, the young people themselves) cited parental influence as a possible reason why many young people did not lead healthy, active lifestyles, these approaches should aim to develop parents' ability to effectively promote health enhancing behaviours. More sophisticated pedagogies and greater responsibilisation of parents may not, however, overcome the material and contextual barriers many young people and families face in terms of regular physical activity, nutritious eating, and the general translation of health knowledge to health behaviour. However, this should not deter teachers from trying to improve their teaching of health knowledge.

Most of the young people in the study considered that their school encouraged them to lead healthy lifestyles although some suggested ways in which schools could improve in this regard by, for example: making it more fun/positive; offering healthy/healthier school meals; engaging them in discussions about healthy eating; explaining the consequences of unhealthy lifestyles; not ignoring pupils who are no good at PE; not making PE kit rules too strict; offering a broader range of activities in PE; and providing more varied clubs at lunchtime or after school and encouraging attendance at these. With respect to the above, two 15 year olds suggested:

Show us the good side to it, the things that are positive (Case Study School A).

I think it is basically like having fun with like being healthy because you know, some people don't actually care if I am eating too much chocolate or if it is not healthy for me. Like teenagers, we want to have fun (Case Study School C). 
The young people cited many sources of information about leading healthy, active lifestyles such as teachers, family, friends, media and clubs and they held varying views on the accuracy of the health information they received. Typical responses included:

I think school is probably one of the most accurate places you could probably get it from, because other places like the internet, they are not always the truth (Case Study School D, 12 years old).

You trust school because you know you can trust school because school can't tell you anything that is a lie, but the media can (Case Study School A, 15 years old).

Some of it is reliable but sometimes they exaggerate it a bit because they want to try and scare you so that you do have a healthy lifestyle (Case Study School B, 13 years old).

I think it's biased because the government wants schools to tell us to be healthy so they're not going to tell us both sides, they'll tell us the government's (Case Study School E, 15 years old).

Burrows and colleagues (2002) similarly found that young people acquired knowledge from a range of sources. Particular attention has been paid to 'public pedagogies' which refer to learning that extends well beyond the boundaries of formalised education sites and operates within a wide variety of social institutions and formats such as the media (Giroux, 2004; Rich, 2011). There is a recognition that the acquisition of knowledge from a range of sources can result in young people receiving mixed messages and developing complex and confused conceptions, as found in this study.

Although this study revealed inadequacies in young people's understandings of health, fitness and physical activity, the majority of the teachers considered that their pupils had good knowledge and understanding of health, fitness and physical activity. In particular, they thought that their pupils knew about the importance of being active, not having too 
much of the 'wrong' foods, eating five portions of fruit and vegetables a day, drinking lots of water and not smoking/drinking alcohol. This suggests that the majority of the teachers did not recognise the inadequacies in their pupils' understandings which is highly possible given that many teachers' understandings of health and fitness were as simplistic and problematic as those demonstrated by their pupils.

Some teachers, however, did consider that their pupils had limited knowledge about the benefits of physical activity such as its role in healthy weight management. For example, a teacher from Case Study School C described the pupils from her school as somewhat confused about the effects of eating and exercise on body size and shape and she considered that they would benefit from this being addressed in her school. This confusion may have stemmed from some children conflating health and fitness with being thin, while also believing that exercise helps to maintain or gain thinness, yet recognising themselves as thin and having unhealthy diets and not being active. In effect, children are weighing up information from school (such as if you do not eat a healthy diet and exercise, you will become fat/overweight) with their own experiences of, in some cases, not having a healthy diet and not exercising but still being thin; this underlines the complexity of the relationship between diet, exercise and body weight which needs to be acknowledged by teachers as well as pupils.

Another teacher from Case Study School A thought that the pupils in her school did not fully understand what constituted 'physical activity' and undervalued some routine, habitual activities such as walking, and two other teachers considered that their pupils would benefit from knowing more about the consequences of an unhealthy lifestyle, with one of these stating:

I think the stark facts of what actually happens if you don't do exercise and you eat badly. The combination of a bad diet and not being active and what it can actually do to you (Case Study School B). 
A teacher from Case Study School F was of the opinion that her pupils would benefit from knowing more about the specific benefits of different types of sports and activities.

Teachers in the study were asked what they thought the key messages were that needed to be conveyed to young people to help promote healthy, active lifestyles. The vast majority referred to the importance of a healthy diet and exercising and some also mentioned the importance of a good night's sleep and finding a good 'balance' in life. Illustrative quotations included:

To find ways to take part in physical activity that is going to lead to lifelong participation; to find something that you enjoy; to balance it with a healthy diet; to get adequate sleep, because I think that a lot of the students we work with don't have a nutritional diet and they don't have enough sleep (Case Study School C).

I think just trying to encourage them to look to the future and be aware of the way they operate now is what will impact on their futures. Try and make them aware of older family members that maybe haven't adopted healthy lifestyles and the impact it could have (Case Study School F).

The following were highlighted by many teachers in the study as important to teach to help young people adopt healthy, active lifestyles: the links between physical and mental health and physical activity; the effects of adopting and not adopting healthy, active lifestyles; how much physical activity should be done; how being physically active can become part of a lifestyle; balancing work and play; and the value of having breakfast. Some teachers also referred to the importance of: providing enough information for young people to be able to make informed choices; making young people think; and challenging views such as that 'it is not cool for girls to be sporty' and that 'being thin is good'. The latter resonates with the call for a critical approach to the teaching of health issues within the curriculum (Burrows et al., 2009). 
So, whilst there is an expectation that schools will help young people lead healthy, active lifestyles, information alone is clearly insufficient to bring about positive behaviour change. Dilemmas abound in this area as many teachers in this study considered that the problem lies in young people not acting upon information provided but did not recognise their own inadequacies. Teachers' lack of preparedness for promoting physical activity was found by Cale (2000) and Alfrey and colleagues (2012), and led to a call by Armour \& Harris (2013) for the development of new PE-for health pedagogies. More recently, Harris (2014) revealed that PE teacher education is not adequately preparing future PE teachers to promote healthy, active lifestyles which undoubtedly compounds the problem. Furthermore, although healthrelated physical education resources have been produced from time to time to assist teachers in this area of work (e.g. Harris, 2000), it cannot be assumed that they are readily accessible or even used by teachers and consequently the potential for resources alone to fundamentally change pedagogical approaches to the teaching of health within curriculum PE is limited (Cale, Harris \& Leggett, 2002). Given this, it is possible that some of the issues identified in this paper such as young people holding reductive, limited and limiting conceptualisations of health, fitness and physical activity are unwittingly created and compounded by inadequately prepared teachers holding similarly reductive, limited and limited conceptualisations.

The findings of this study emphasise the need for physical education teachers to be better prepared to address health issues within their subject and to more effectively promote physical activity. This requires a critical approach to health education involving sophisticated teaching and learning methodologies, including communicating up-to-date, accurate information associated with the adoption of healthy, active lifestyles and assisting young people in dealing with mixed, conflicting and changing messages from a range of sources in order to reduce uncertainty and minimise complacency.

\section{Conclusion and Recommendations}


The purpose of this study was to explore young people's knowledge and understanding of health, fitness and physical activity and to draw upon critical discourse analysis to discuss the findings and to offer suggestions to enhance associated teaching and learning and to affect behavioural change. The findings generally support those of previous studies over the last 25 years suggesting that young people generally have simplistic knowledge and somewhat confused understandings of health, fitness and physical activity which may partially account for the discrepancy between this and their actual health behaviours. Young people's confusion was demonstrated in this study in a number of ways, such as conflating healthy activity with a limited number of sports and displaying other anomalies such as needing to eat more fruit to become fit. It appears that these young people struggle to make sense of health information received from a range of sources (in particular schools and popular culture) and are lacking in the foundation knowledge and understanding associated with leading healthy, active lifestyles.

The study's findings reveal that young people's knowledge and understanding of health, fitness and physical activity concepts has developed little in recent decades which is perhaps unsurprising given teachers' limited understandings and the healthism-influenced ways that health/fitness has been taught in schools and covered in the popular media. This suggests that action is required to address inadequate pedagogies and public health messages which result in deficits in student understanding. It is, therefore, recommended that a critical approach is adopted in order to challenge the perpetuation of the healthism discourse and that this learning is prioritised, its breadth and depth increased, and its relevance to young people enhanced. Understanding of these concepts needs to: be broadened beyond physical activity, diet and weight; go beyond a basic level; build upon prior knowledge; and demonstrate progression over time. A properly co-ordinated whole school approach to teaching health, as advocated in Healthy Schools initiatives (Deschenes et al., 2003), should help young people connect learning from across a range of school subjects as well as from external sources. Young people would benefit from support in 
taking on board up-to-date health, fitness and physical activity content, with dealing with inaccurate and inappropriate messages and resolving differences in information and the uncertainty of knowledge, and relating their learning to themselves and their everyday lives. We, therefore, support Burrows and colleagues' (2002) call to explicitly address the social constructions of health and fitness and the ways in which these are constituted in teaching about physical activity and health.

In $\mathrm{PE}$, in particular, the learning should challenge the narrow and reductive focus many young people and teachers have concerning health, fitness and physical activity. For example, as well as recognising that physical activity contributes to 'physical' health, all young people should be aware of and experience its psychological and social benefits and, over time, they should develop greater understanding of how physical activity benefits health. Young people should also know the physical activity recommendations for their age and be guided as to how to meet them. They should appreciate that routine, habitual activities can lead to health and fitness gains and should be aware that it is possible to be healthy and fit 'at any size' and that it is not essential to be good at sport to be regularly active. All of this requires new PE for health pedagogies (Armour \& Harris, 2013).

This paper has presented and discussed a number of issues relating to young people's knowledge and understanding of health, fitness and physical activity and associated behaviours. Increased awareness of these issues and of the divide between health knowledge and understanding and health behaviour and associated dilemmas has the potential to drive much needed development in critical PE-for-health pedagogies which challenge the dominance and stability of the healthism discourse and more effectively promote healthy, active lifestyles amongst young people.

\section{Acknowledgements}

The authors would like to acknowledge the support of the British Heart Foundation National Centre for Physical Activity and Health which commissioned this research. 


\section{References}

Alfrey, L., Cale, L., \& Webb, L. A. (2012). Physical education teachers' continuing professional development in health-related exercise. Physical Education and Sport Pedagogy, 17(5), 477-491.

Armour, K., \& Harris, J. (2013). Making the case for developing new PE-for-health pedagogies. Quest, 65(2), 201-209.

Australian Curriculum and Reporting Authority (2011). Australian curriculum. Retrieved from http://www.acara.edu.au/curriculum/curriculum.html

Bauman, A. E., Reis, R. S., Sallis, J. F., Wells, J. C. Loos, R. J. F. et al. (2012). Correlates of physical activity: why are some people physically active and others not? Lancet, 380, 258271.

Brusseau, T. A., Kulinna, P. H., \& Cothran, D. J. (2011). Health and physical activity content knowledge of Pima children. Kinesiology, Sport Studies and Physical Education Faculty Publications. Paper 64. State University of New York: The College at Brockport.

Burrows, L., \& Wright, J. (2004). The good life: New Zealand children's perspectives on health and self. Sport, Education and Society, 9(2), 193-205.

Burrows, L., Wright, J. and Jungersen-Smith, J. (2002). 'Measure your belly': New Zealand children's constructions of health and fitness. Journal of Teaching in Physical Education, 22(1), 39-48.

Burrows, L., Wright, J., \& McCormack, J. (2009). Dosing up on food and physical activity: New Zealand children's ideas about 'health'. Health Education Journal, 68(3), 157-169.

Cale, L. (2000). Physical activity promotion in schools - PE teachers' views. European Journal of Physical Education, 5(2), 158-167.

Cale, L., Harris, J., Duncombe, R., \& Musson, H. (2011). Supporting secondary schools in the effective promotion of physical activity. Loughborough: British Heart Foundation National Centre for Physical Activity. 
Cale, L., Harris, J., \& Leggett, G. (2002). Making a difference? Lessons learned from a health-related exercise resource. Bulletin of Physical Education, 38(2): 145-160.

Cardon, G. \& Bourdeaudhuij, I. (2002). PE and physical activity in elementary schools in Flanders. European Journal of Physical Education, 7(1), 5-18.

Department for Education (2013). National curriculum in England: Physical education programmes of study. www.gov.uk

Deschenes et al. (2003). Comprehensive approaches to school health promotion: how to achieve broader implementation. Health Promotion International, 18(4), 387-396.

Desmond, S, M., Price, J. H., Lock, R. S., Smith, D. \& Stewart, P. W. (1990). Urban black and white adolescents' physical fitness status and perceptions of exercise. Journal of School Health, 60(5), 220-226.

DiLorenzo, T. M., Stucky-Ropp, R. C., Vander Wal, J. S., \& Gotham, H. J. (1998). Determinants of exercise among children. II. Longitudinal analysis. Preventive Medicine 27(3), 470-477.

Dixey, R., Sahota, P., Atwal, S., \& Turner, A. (2001). "Ha ha, you're fat, we're strong" a qualitative study of boys' and girls' perceptions of fatness, thinness, social pressures and health using focus groups. Health Education, 101(5), 206-216.

Fairclough, N., Mulderrig, J., \& Wodak, J. (2011). Critical discourse analysis. In: Teun A. Van Dijk (Ed.), Discourse Studies: A Multidisciplinary Introduction, pages 357-378.

Gard, M., \& Pluim, C. (2014). Schools and Public Health: Past, Present, Future. Lexington Books.

Giroux, H. (2004). Cultural studies, public pedagogy and the responsibility of Intellectuals. Communication and Critical/Cultural Studies, 1(1), 59-79.

Harris, J. (1993). Young people's perceptions of health, fitness and exercise. British Journal of Physical Education Research Supplement 13. 5-9.

Harris, J. (1994). Young people's perceptions of health, fitness and exercise: implications for the teaching of health-related exercise. Physical Education Review 17(2), 143-151. 
Harris, J. (2000). Health-Related Exercise in the National Curriculum. Key Stages 1 to 4. Leeds: Human Kinetics.

Harris, J. (2014). Physical education teacher education students' knowledge, perceptions and experiences of promoting healthy, active lifestyles in secondary schools. Physical Education and Sport Pedagogy, 19(5), 466-480.

Health and Social Care Information Centre (2015). Statistics on obesity, physical activity and diet England 2015. Leeds: Health and Social Care Information Centre. www.hscic.gov.uk

Harro, M., \& Riddoch, C. (2000). Physical activity. In: N. Armstrong \& W. Van Mechelen (Eds.), Paediatric Exercise Science and Medicine, pp. 78-84. Oxford: Oxford University Press.

Johnson, R.B., Onwuegbuzie, A.J. and Turner, L.A. (2007). Toward a definition of mixed methods research. Journal of Mixed Methods Research, 1(2): 112-133.

Keating, X. D., Harrison, L., Chen, L., Xiang, P., Lambdin, D., Dauenhauer, B., Rotich, W. and Pinero, J. C. (2009). An analysis of research on student health-related fitness knowledge in K-16 physical education programs. Journal of Teaching in Physical Education, 28(3): 333-349.

Kirk, D., \& Colquhoun, D. (1989). Healthism and physical education. British Journal of Sociology of Education, 10, 417-434.

Kulinna, P. H. (2004). Physical activity and fitness knowledge: How much 1-6 grade students know. International Journal of Physical Education, 41(3), 111-121.

Lee, I., Shiroma, E. J., Lobelo, F., Puska, P., Blair, S., \& Katzmarzyk, P. T. (2012). Effect of physical inactivity on major non-communicable diseases worldwide: An analysis of burden of disease and life expectancy. The Lancet 380, 219-229.

Lee, J., \& Macdonald, D. (2009). Rural young people and physical activity: understanding participation through social theory. Sociology of Health and IIIness, 31(3), 36-374. 
Lee, J., \& Macdonald, D. (2010). 'Are they just checking our obesity or what?' The healthism discourse and rural young women. Sport, Education and Society, 15(2), 203-219.

Merkle, D. G., \& Treagust, D. F. (1993). Student knowledge of health and fitness concepts and its relation to locus of control. School Science and Mathematics, 93, 355-359.

Office for Standards in Education (OFSTED) (2005). Physical education in secondary schools. London: OFSTED.

O'Shea, J. M., \& Beausoleil, N. (2012). Breaking down 'healthism': Barriers to health and fitness as identified by immigrant youth in St. John's, NL, Canada. Sport, Education and Society, 17(1), 97-112.

Pasco, J.A., Jacka, F.N., Williams, L.J., Brennan, S.L., Leslie, E. and Berk, M. (2011). Don't worry, be active: Positive affect and habitual physical activity. Australian and New Zealand Journal of Psychiatry, 45(12), 1047-1052.

Placek, J.H., Griffin, I.L., Dodds, P., Raymond, C., Tremino, F., \& James, A. (2001). Middle school students' conceptions of fitness: the long road to a healthy lifestyle. Journal of Teaching in Physical Education 20, 314-323.

Powell, D., \& Fitzpatrick, K. (2015). 'Getting fit basically just means, like, non-fat': children's lessons in fitness and fatness. Sport, Education and Society, 20(4), 463-484.

Rich, E. (2011). 'I see her being obesed!': Public pedagogy, reality media and the obesity crisis. Health, 15(1), 3-21.

Ritchie, J., \& Lewis, J. (2003). Qualitative research practice: a guide for social science students and researchers. Thousand Oaks, CA: Sage.

Roth, M., \& Stamatakis, E (2010). Linking young people's knowledge of public health guidelines to physical activity levels in England. Pediatric Exercise Sciences, 22, 467-476. St. Leger, L. (2004). What's the place of schools in promoting health? Are we too optimistic? Health Promotion International, 19(4), 405-408. 
Stewart, S., \& Mitchell, M. (2003) Instructional variables and student knowledge and conceptions of fitness. Journal of Teaching in Physical Education 22(5), 533-551.

Thomas Thomas, K. (2004). Riding to the rescue while holding on by a thread: Physical activity in the schools. Quest, 56(1), 150-170.

Wen, C. P., \& Wu, X. (2012). Stressing harms of physical inactivity to promote exercise. The Lancet, 380(9838), 192-193.

Zhu, W., Safrit, M., \& Cohen, A (1999). The national health-related physical fitness knowledge test: FitSmart test user manual (high school edition). Champaign, IL: Human Kinetics. 